\title{
Structural and Optical Analysis of Ag Nanoparticles assisted Vertically Aligned TiO2 Nanowires based photoanode for Dye-sensitized Solar Cells Application
}

Biraj Shougaijam ( $\sim$ biraj.sh89@gmail.com )

Manipur Technical University https://orcid.org/0000-0002-3556-0126

Salam Surjit Singh

Manipur Technical University

\section{Research Article}

Keywords: Flexible, GLAD, Nanoparticle, Nanowires, Plasmonic, TiO2

Posted Date: March 16th, 2021

DOl: https://doi.org/10.21203/rs.3.rs-288900/v1

License: (a) (1) This work is licensed under a Creative Commons Attribution 4.0 International License.

Read Full License 


\title{
Structural and Optical Analysis of Ag Nanoparticles assisted Vertically Aligned $\mathrm{TiO}_{2}$ Nanowires based photoanode for Dye- sensitized Solar Cells Application
}

\author{
Biraj Shougaijam $^{1}$ and Salam Surjit Singh ${ }^{1}$ \\ ${ }^{1}$ Department of Electronics and Communication Engineering, Manipur Technical University, Takyelpat-795004, \\ Manipur, India
}

biraj.sh89@gmail.com, Orcid Id: 0000-0002-3556-0126

surjitsalam19@gmail.com, Orcid Id: 0000-0002-0384-4757

\begin{abstract}
:
In this work, vertically aligned $\mathrm{TiO}_{2}-\mathrm{Nanowires}\left(\mathrm{TiO}_{2}-\mathrm{NWs}\right)$ and $\mathrm{Ag}$ Nanoparticles assisted $\mathrm{TiO}_{2}$ Nanowires (TAT-NWs) were deposited on glass and flexible PET substrates using the Glancing Angle Deposition (GLAD) technique. The morphology and structural analysis of the samples manifest the successful deposition of vertically aligned $\mathrm{TiO}_{2}-\mathrm{NWs}$ and TAT-NWs. The HR-TEM image of $\mathrm{TiO}_{2}-\mathrm{NWs}$ shows the polycrystalline nature. Further, the XRD result confirms the polycrystalline nature of both the $\mathrm{TiO}_{2}-\mathrm{NWs}$ and TAT-NWs samples. Besides, the HR-TEM image confirms the presence of small crystal grains of Ag Nanoparticles (Ag-NPs) at the mid of the annealed TAT-NWs. It is evident from the Selective Area Electron Diffraction (SAED) analysis of the $\mathrm{TiO}_{2}$-NWs and annealed TAT-NWs that the crystallinity of $\mathrm{TiO}_{2}$ present in the annealed TAT-NWs improves after annealing. The absorption spectrum analysis of TAT-NWs deposited on glass substrate shows enhance absorption peak in the visible region with a maximum peak at $\sim 463 \mathrm{~nm}$ wavelength compare to the $\mathrm{TiO}_{2}-\mathrm{NWs}_{\mathrm{s}}$, which may be attributed to the Surface Plasmon Resonance (SPR) effect of Ag-NPs. Further, it is interesting to observe that the TAT-NWs deposited on PET substrate show further absorption enhancement in the UV and visible region. In addition, the Photoluminescence analysis reveals that the bandgap of the $\mathrm{TiO}_{2}-\mathrm{NWs}_{\mathrm{s}}$ is $\sim 3.12$ $\mathrm{eV}$, which supports the bandgap extracted from the Tauc plot. Therefore, the proposed method of fabricating TAT-NWs on glass and flexible ITO coated PET substrate using the GLAD technique may be applicable for developing novel photoanode for Dye-sensitized Solar Cells (DSSCs) and other optoelectronic applications.
\end{abstract}

Keywords: Flexible, GLAD, Nanoparticle, Nanowires, Plasmonic, $\mathrm{TiO}_{2}$

\section{Introduction}

Titanium dioxide $\left(\mathrm{TiO}_{2}\right)$ is one of the most extensively investigated materials for various applications like photo-catalysis, photo degradation, energy storage, photovoltaic devices and optoelectronic devices [1, 2]. In the last decade, one-dimensional (1D) $\mathrm{TiO}_{2}$ nanostructures have been significantly studied because of their ability to enhance the light absorption due to scattering of lights inside the nanostructure, which facilitates the photocatalytic reactions and by providing the direct pathway for charge carrier [3]. Many researchers are trying to develop highly efficient photovoltaic devices based on $1 \mathrm{D}-\mathrm{TiO}_{2}$ nanostructure as photoanode. It may be noteworthy to mention that the market demand for clean renewable energy sources is increasing globally day-byday. In this sector, Dye-sensitized solar cells (DSSCs) will play a major role in fulfilling this market demand because of their potential for low-cost production, ease of fabrication, environmentally friendly and the possibility to fabricate on a flexible substrate [4]. Many researchers are trying to improve the efficiency of DSSCs since their invention by O'Regan and Gratzel in 1991 [5]. The highest reported efficiency of DSSCs is $\sim 12.8 \%$ [6], which is lower than that of solar cells like perovskite solar cells [7], thin-film solar cells [8], polymer solar cells [9] and crystalline silicon ( $\mathrm{Si}$ ) solar cells [10]. Nevertheless, the efficiency of DSSCs can be improved by enhancing the photon absorption and making electron transport easier in various layers namely photoanode, sensitizers, electrolyte and counter electrode. One of the most important layers of DSSCs is the photoanode, which plays an important role in the absorption of photon and electron transport to the external circuit of the cell to generate power. Among the metal-oxides, $\mathrm{TiO}_{2}$ nanostructure is the most commonly used material as photoanode for DSSCs because of its unique properties like photocatalytic, less charge carrier recombination rate, non-toxic, environment-friendly and chemical stability [11]. However, the large bandgap of $\mathrm{TiO}_{2}$ nanostructure hampers the absorption of light in the visible region, which affects its performance in wide applications. To overcome the issues many researchers are trying to modify $\mathrm{TiO}_{2}$ nanostructure-based photoanode by putting metal nanoparticles (NPs), doping of material and by changing the morphology to boost the overall performance of DSSCs [12-14]. 
The main issue of this layer is the increase in the thickness of the photoanode while trying to improve the photon absorption and increase in the recombination of photo-excited electrons inside the cell, which is responsible for lowering the efficiency $[15,16]$. In recent years, researchers are trying to address these issues by developing vertically oriented one-dimensional (1D) metal-oxide nanostructures decorated with metal nanoparticles (MNPs) $[17,18]$. The metal NPs decorated metal-oxide nanostructures improve the efficiency by creating a short electron pathway through the 1D structure, at the same time, enhancing the photon absorption through localized surface plasmon resonance of MNPs. This effect of localized surface plasmon resonance depends on the shapes, sizes and types of metal used. Therefore, synthesizing the desired size of metal NPs to incorporate with metal-oxide needs a controlled growth mechanism. Further, Gold (Au) and Silver (Ag) are the most widely used novel metals due to their tuneable Surface Plasmon Resonance (SPR) effect in the visible region. However, Ag is relatively low cost compared to Au and the SPR effect can be tune in the visible region by changing the shape and sizes [14]. Again, controlling the size of NPs decorated on the metal-oxide is still challenging since the controlled growth technique need state-of-the-art fabrication technique [19]. Moreover, most of the recently reported techniques are not catalytic-free and employed more than one synthesis technique to develop photoanode for DSSCs [15, 20]. The glancing angle deposition technique (GLAD) is a cost-effective technique that can grow vertically oriented nanowires and metal NPs without using any catalyst $[21,22]$. Therefore, it will be interesting to develop Ag-NPs embedded $\mathrm{TiO}_{2}-\mathrm{NWs}$ based photoanode using the GLAD technique.

In this work, $\mathrm{TiO}_{2}-\mathrm{NWs}$ and $\mathrm{TiO}_{2}-\mathrm{NWs} / \mathrm{Ag}-\mathrm{NPs} / \mathrm{TiO}_{2}-\mathrm{NWs}$ (TAT-NWs) based photoanode was fabricated using the GLAD technique without using any catalyst on glass and flexible PET substrate. The morphology, structural and optical properties of the samples are discussed in this work. The morphology and structural properties were also characterized using Filed Emission-Scanning Electron Microscopy (FE-SEM), High-resolution Transmission Electron Microscopy (HR-TEM) and X-ray diffraction (XRD). The optical properties of the samples were also analysed using UV-Vis spectroscopy and photoluminescence spectroscopy.

\section{Experimental Details}

Vertically oriented $\mathrm{TiO}_{2}$ nanowire $\left(\mathrm{TiO}_{2}-\mathrm{NWs}\right.$ ) and $\mathrm{TiO}_{2}-\mathrm{NWs} / \mathrm{Ag}-\mathrm{NPs} / \mathrm{TiO}_{2}-\mathrm{NWs}$ (TAT-NWs) are deposited on glass and flexible PET substrates using Glancing Angle Deposition (GLAD) inside the E-beam evaporation system (Model No.: Smart Coat 3.0, HHV India). The $\mathrm{TiO}_{2}$-NWs and Silver (Ag) nanoparticles were deposited using $\mathrm{TiO}_{2}$ (99.999\% pure, Tecnisco Advanced Materials Pte Ltd, Singapore) and Ag (99.999\% pure, Tecnisco Advanced Materials Pte Ltd, Singapore) source material. A special GLAD system was integrated inside the E-beam chamber, which allowed changing of the desired angle through the axis of the GLAD system. The process of forming vertically oriented $\mathrm{TiO}_{2}$-NWs on the substrate through the GLAD process has been discussed in our previous work [23]. Similarly, in this work, the GLAD technique was employed to grow unique $\mathrm{TiO}_{2}$ nanostructures embedded with Ag-NPs without using any catalyst. The samples were rotated at speed of $30 \mathrm{rpm}$, which are kept at a distance of $20 \mathrm{~cm}$ from the evaporating source material during the deposition. The e-beam chamber was clean properly using acetone before making the chamber vacuumed. The chamber pressure was initially maintained at $\sim 6 \times 10^{-6} \mathrm{mbar}$. It is observed that the chamber pressure gradually drops to $\sim 2 \times 10^{-5} \mathrm{mbar}$ during the initial deposition process, which may be due to the release of oxygen gas from the evaporation material. In the first round of deposition, $\mathrm{TiO}_{2}$-NWs $(240 \mathrm{~nm})$ samples were deposited on glass $(1 \mathrm{~cm} \mathrm{x} 1 \mathrm{~cm})$ substrate using the GLAD technique. And, in the second round of deposition, $\mathrm{TiO}_{2}$-NWs $(120 \mathrm{~nm})$ were first deposited on glass $(1 \mathrm{~cm} \mathrm{x} 1 \mathrm{~cm})$ and ITO coated PET $(1 \mathrm{~cm} \times 1 \mathrm{~cm})$ substrates, followed by Ag NPs $(30 \mathrm{~nm})$ deposition on the top to $\mathrm{TiO}_{2}-\mathrm{NWs}(120 \mathrm{~nm})$. Further, $\mathrm{TiO}_{2}-\mathrm{NWs}(120 \mathrm{~nm})$ were deposited above the $\mathrm{Ag}-\mathrm{NPs}(30 \mathrm{~nm}) / \mathrm{TiO}_{2}-$ NWs $(120 \mathrm{~nm})$. Finally, we achieved the staking of $\mathrm{TiO}_{2}-\mathrm{NWs}(120 \mathrm{~nm}) / \mathrm{Ag}-\mathrm{NPs}(30 \mathrm{~nm}) / \mathrm{TiO}_{2}-\mathrm{NWs}(120 \mathrm{~nm})$ (TAT-NWs) samples using the GLAD technique without using any catalyst. The deposition rate was maintained at $\sim 0.6 \AA$ Asec for 12 minutes for each deposition of $\mathrm{TiO}_{2}(30 \mathrm{~nm})$ and 7 minutes for the deposition of $\mathrm{Ag}(30 \mathrm{~nm})$

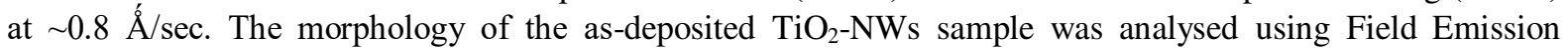
Scanning Electron Microscope (FE-SEM) (Sigma 300 Zeiss). Further, the structural properties of as-deposited $\mathrm{TiO}_{2}$-NWs and annealed TAT samples were analysed by High-resolution Transmission Electron Microscopy (HRTEM) (JEM-2100 JEOL). Finally, the as-deposited $\mathrm{TiO}_{2}-\mathrm{NWs}$ and annealed TAT samples were also characterized by X-ray diffraction (XRD) using X-PertPro PanAnalytical with $\mathrm{Cu}$ K-alpha radiation $(\lambda=1.54060 \AA)$ which is operated at $30 \mathrm{~mA}$ and $40 \mathrm{kV}$. The optical properties were analysed for $\mathrm{TiO}_{2}-\mathrm{NWs}$ and TAT samples using UVVis spectrophotometer (AN-UV-6500N ANTech) under the wavelength range of $370 \mathrm{~nm}$ to $800 \mathrm{~nm}$. The samples were also characterized using a Photoluminescence spectrophotometer (F-7000 Fluorescence Spectrophotometer HITACHI) under an excitation wavelength of $340 \mathrm{~nm}$ using a $370 \mathrm{~nm}$ filter. 


\section{Result and Discussion}

\subsection{Morphology and structural analysis}

\subsubsection{FE-SEM analysis}

The top view FESEM image of the sample shown in Fig. 1 reveals the successful growth of vertically aligned TAT-NWs on glass substrate using GLAD techniques by e-beam evaporation technique. It is observed that the average diameter of TAT-NWs is ranging from $\sim 20 \mathrm{~nm}$ to $\sim 100 \mathrm{~nm}$ as seen from the inset of Fig. 1. The calculated average diameter of the $\mathrm{TiO}_{2} \mathrm{NWs}$ is $50 \mathrm{~nm}$. The porous nature observed from the top view reveals the formation TAT-NWs. Similar morphology is observed from the top view image of GLAD deposited $\mathrm{TiO}_{2} \mathrm{NWs}$ [24]. Such nanostructure enhanced the photon absorption due to an increase in the surface-to-volume ratio. In addition, this unique nanostructure may help in designing flexible solar cells for trapping more incident photons [25]. It is also observed that larger diameter NWs are formed, which may be due to the cluster formation at the initial stage of nucleation [26].

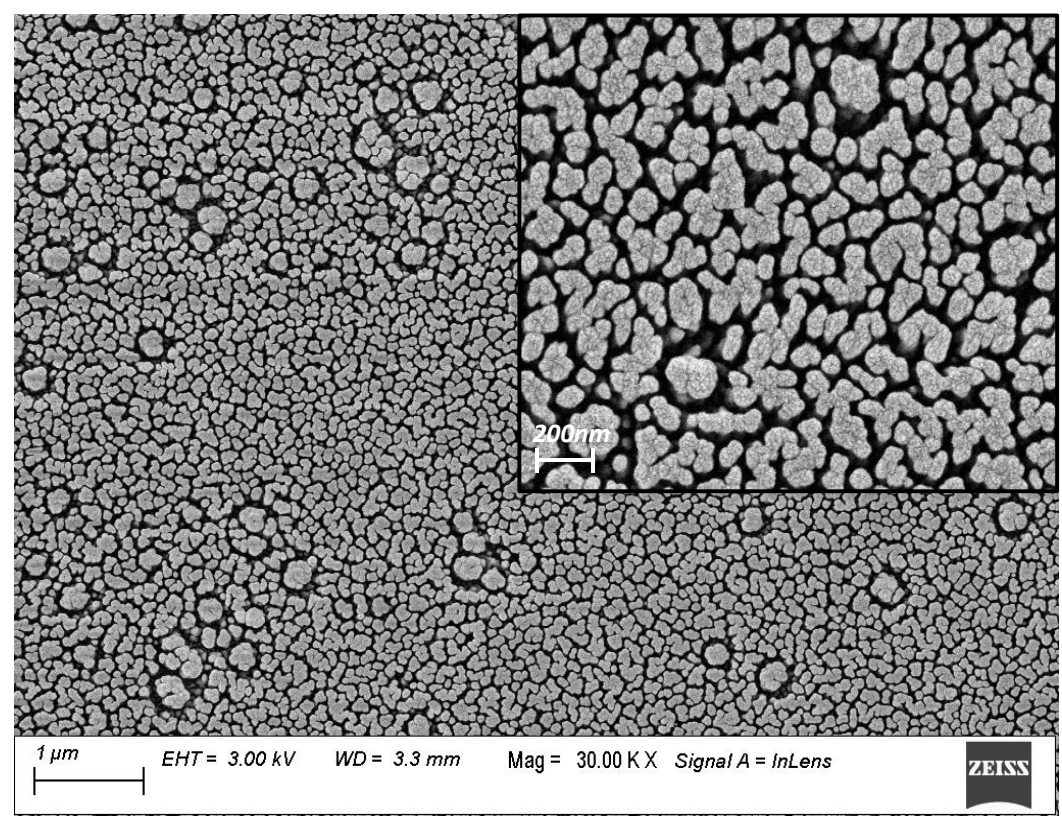

Fig. 1 Top view FE-SEM image of as-deposited TAT-NWs sample and inset shows the magnified image showing the porous nature of the sample

\subsubsection{TEM analysis}

The TEM images of the as-deposited $\mathrm{TiO}_{2}$-NWs and annealed TAT-NWs are shown in Fig. 2. Fig. 2(a) shows typical $\mathrm{TiO}_{2}-\mathrm{NWs}$ having a diameter of $\sim 20 \mathrm{~nm}$ at the top and a length of $240 \mathrm{~nm}$. The arrow mark in Fig. 2 (a) indicates the growth direction of the $\mathrm{TiO}_{2}$-NWs during the growth process. This result also reveals that the vertically aligned NWs are successfully grown on the substrate by the GLAD technique, which supports the top view image of FE-SEM. The magnified HR-TEM image as shown in Fig. 2(b) reveals the presence of small grains of $\mathrm{TiO}_{2}$ crystal, which indicates that the as-deposited $\mathrm{TiO}_{2}-\mathrm{NWs}$ are polycrystalline in nature. Also, the SAED analysis as shown in the inset of Fig. 2(b) manifest that the as-deposited $\mathrm{TiO}_{2}-\mathrm{NWs}$ are polycrystalline in nature. Further, the annealed TAT-NWs sample shown in Fig. 2(c) reveals that the Ag-NPs are successfully embedded at the middle of the $\mathrm{TiO}_{2}$-NWs. The size of the Ag-NPs deposited at the middle is $\sim 30 \mathrm{~nm}$ indicated by the dotted circle in Fig 2 (c). Again, the SAED analysis of the annealed TAT-NWs sample showing the bright ring patterns indicated the polycrystalline nature of $\mathrm{TiO}_{2}$ and $\mathrm{Ag}$ as shown in the inset of Fig. 2(c). It is also evident from the brighter ring pattern of the SAED result of annealed TAT-NW sample that the crystallinity of the $\mathrm{TiO}_{2}$ is improved after annealing at $500{ }^{\circ} \mathrm{C}$ for one $\mathrm{hr}$ in ambient condition compared to the as-deposited $\mathrm{TiO}_{2}-\mathrm{NWs}$ sample. The total length of TAT-NWs is $270 \mathrm{~nm}$ and the diameter is $\sim 50 \mathrm{~nm}$. The larger diameter of the TAT-NWs may be due to the cluster formation during the initial nucleation process [26]. However, the length of the NWs is precisely controlled using this proposed GLAD technique. The lattice constant calculated from the ring of the SAED result of TAT are 3.70, 1.81, 1.73, $1.62 \AA$ which corresponds to (101), (200), (202) and (211) of anatase $\mathrm{TiO}_{2}$ crystals and 2.56, 2.15, $20.8 \AA$ corresponds to (101), (111) and (210) of rutile $\mathrm{TiO}_{2}$ crystals (JC-PDS No. 84-1286 and JC- 
PDS No. 75-1753). Moreover, the lattice constant 1.92, 1.44 and $0.12 \AA$ extracted from the SAED ring of the TAT-NWs sample corresponds to (200) Ag and (220) Ag crystals of Ag NPs. Further, the annealed TAT-NWs sample shows the presence of small crystal grains of Ag-NPs shown in Fig. 2(d), which supports the SAED result of TAT-NWs. The EDX analysis confirms the presence of Oxygen (O), Titanium (Ti) and Silver (Ag) as shown in Fig. 3. It may be mentioned that the e-beam deposited $\mathrm{TiO}_{2}$ thin film are mostly amorphous [27]. However, Y. M. Abdulraheem et. al. reported that the $\mathrm{TiO}_{2}$ thin film deposited at room temperature is polycrystalline. It is reported that the $\mathrm{TiO}_{2}$ crystallinity can be improved by annealing at above $400{ }^{\circ} \mathrm{C} \mathrm{[28]}$.
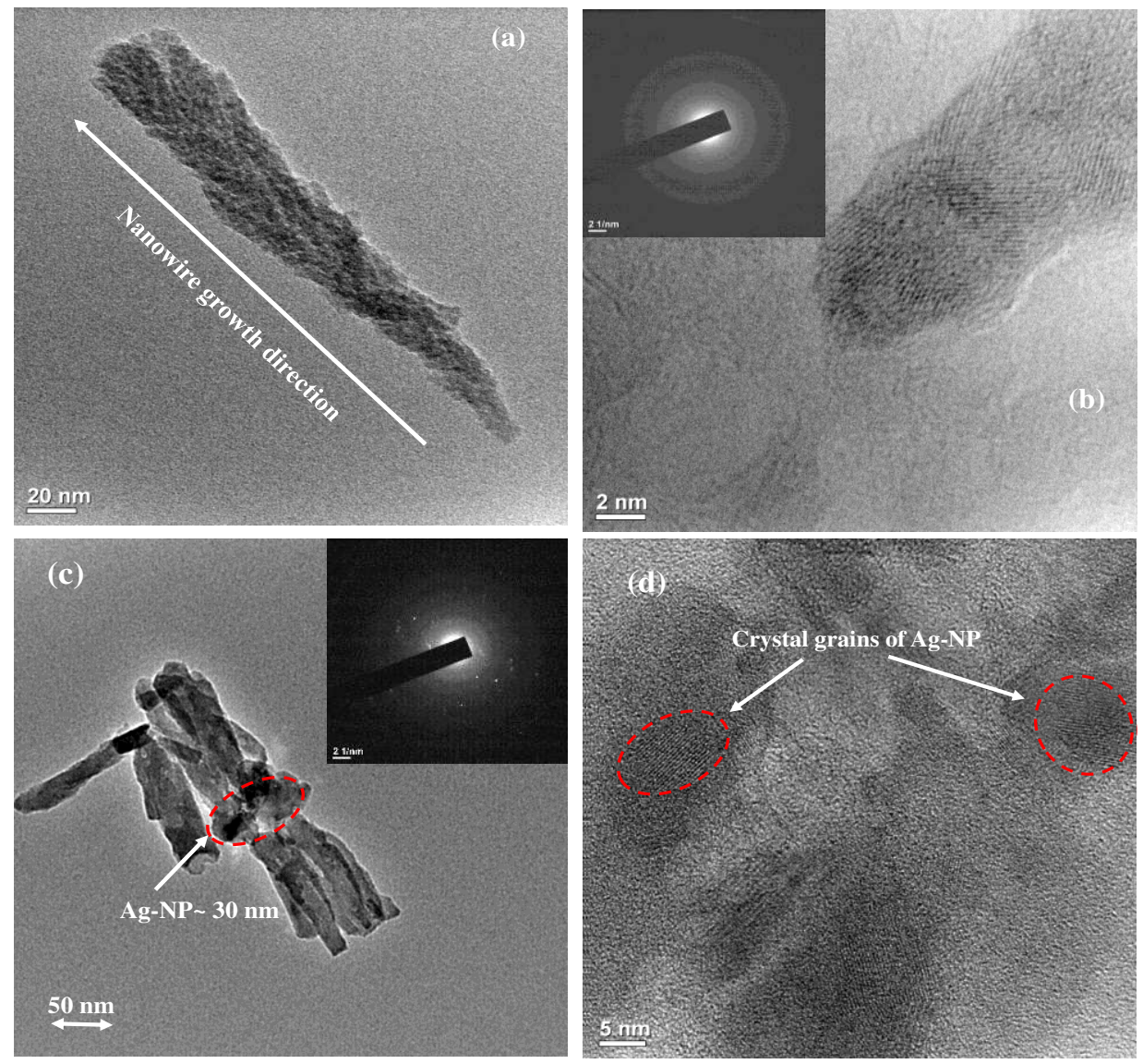

Fig. 2 (a) Shows a typical TEM image of as-deposited $\mathrm{TiO}_{2}-\mathrm{NWs}$, (b) shows the magnified image of top portion of $\mathrm{TiO}_{2}-\mathrm{NWs}$ showing the presence of crystal grain and inset image shows the SEAD results of $\mathrm{TiO}_{2}-\mathrm{NWs}$, (c) Shows the TEM image of annealed TAT-NWs sample and SEAD result in inset shows polycrystalline nature, (d) The magnified TEM image of middle portion of TAT-NWs showing the presence of crystal grain of Ag-NPs.

\subsubsection{XRD analysis}

Fig. 4 shows the XRD results of $\mathrm{TiO}_{2}-\mathrm{NWs}$ and TAT samples deposited on glass substrate using GLAD at $30 \mathrm{rpm}$. It is observed that the weak peaks at $25^{\circ}, 47^{\circ}$ and $55^{\circ}$ are from the crystal lattice of $(101),(200)$ and (211) of anatase $\mathrm{TiO}_{2}$, respectively (JCPDS No. 84-1286). Moreover, the weak peaks at $36^{\circ}$ and $41^{\circ}$ are from the crystal lattice of (101) and (111) of rutile $\mathrm{TiO}_{2}$, respectively (JCPDS No. 75-1753). The TAT-NWs samples also show similar weak peaks from anatase and rutile $\mathrm{TiO}_{2}$ crystal grains. Further, it is very interesting to observe small peaks at $44^{\circ}, 64.8^{\circ}$ which are from Ag crystals (200) and (220) respectively (JCPDS No. 04-0783). The inset of Fig. 4 shows the magnified peak of Ag from (220) crystal at $64.8^{\circ}$. The XRD analysis of the as-deposited $\mathrm{TiO}_{2}-$ NWs and TAT-NWs samples manifests the presence of mixed phases of polycrystalline anatase and rutile $\mathrm{TiO}_{2}$. Further, the XRD result also confirms the presence of Ag-NPs, which were embedded successfully inside the TAT-NWs. It is noteworthy to mention that the e-beam deposited $\mathrm{TiO}_{2}-\mathrm{NWs}$ are mostly amorphous or mixed phases of amorphous and polycrystalline [27, 25]. Alberto Casu et. al. reported the deposition of $\mathrm{TiO}_{2}$ nanostructure having mixed phases [29]. 


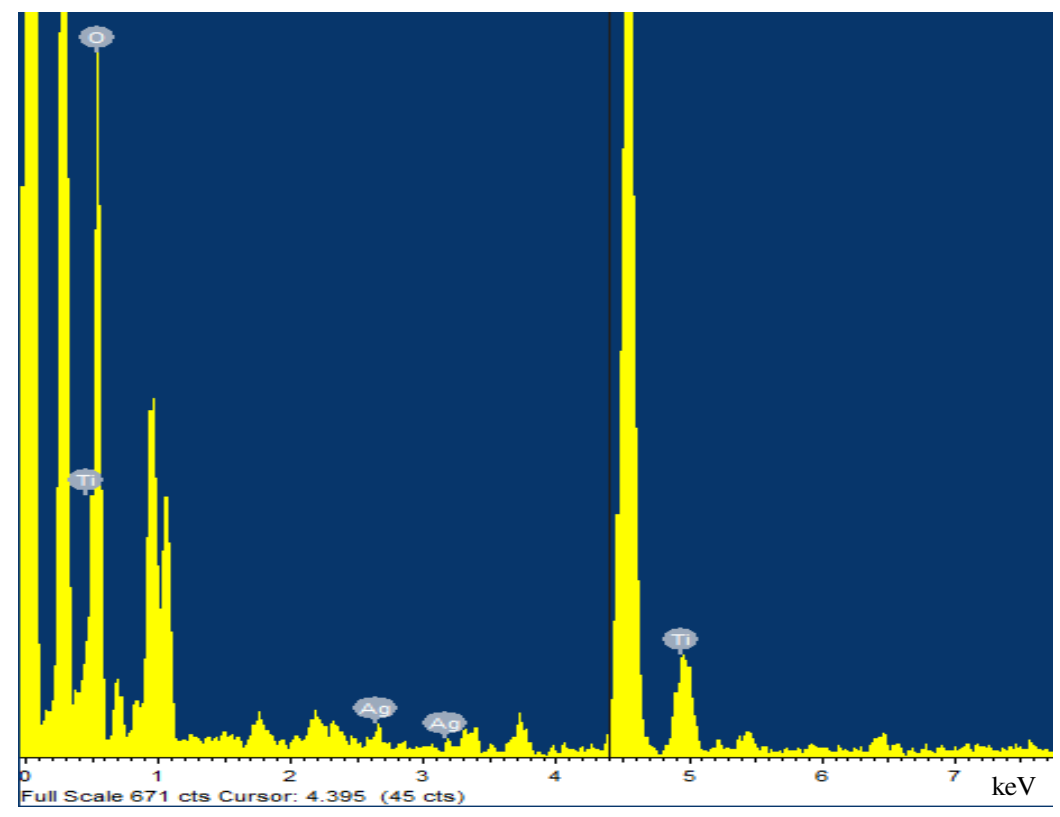

Fig. 3 EDX spectrum showing the elemental presence of TAT Sample

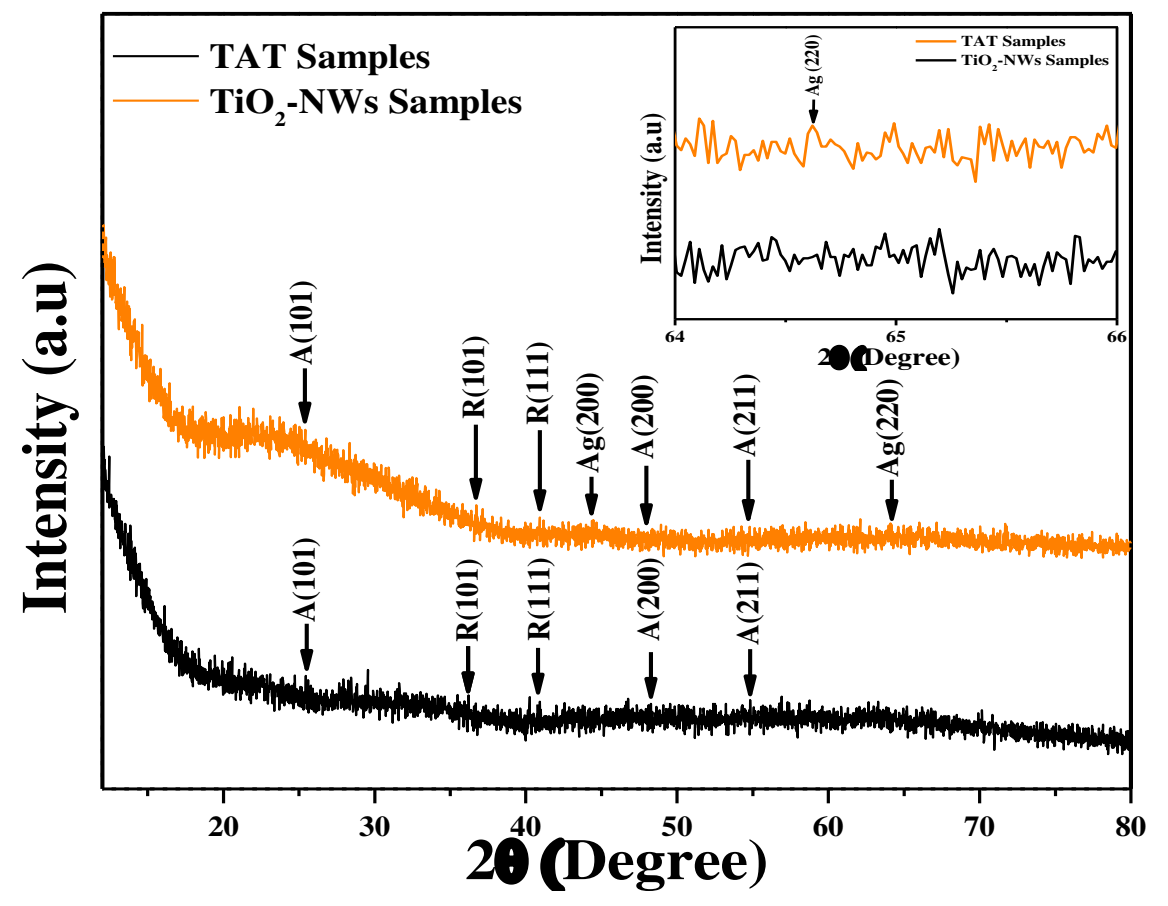

Fig. 4 Shows the XRD result of TAT and $\mathrm{TiO}_{2}$ nanowires deposited at room temperature and the inset shows the magnified resolution-showing a peak from $\mathrm{Ag}$

\subsection{Optical Analysis}

\subsubsection{UV-Vis Spectroscopy}

The optical absorption spectra were measured for the $\mathrm{TiO}_{2}-\mathrm{NWs}$ and TAT-NWs samples, which are deposited on the Glass and PET substrates. These two samples were scanned from $340 \mathrm{~nm}$ to $800 \mathrm{~nm}$ wavelength ranges at room temperature to analyse the absorption spectra of the samples. The absorption intensity of the samples was recorded using UV-Vis Spectrophotometer (AN-UV-6500N, ANTech). Fig. 5 shows the absorption spectra for $\mathrm{TiO}_{2}$-NWs, TAT-NWs deposited on the glass substrate and TAT-NWs deposited on PET substrate. TiO $2-\mathrm{NWs}$ reveals a stronger absorption peak in the ultraviolet (UV) region, which is due to the transition of an excited electron from the valence band to the conduction band [30]. It is observing that TAT-NWs deposited on glass substrate shows enhance absorption in the visible region as compare to $\mathrm{TiO}_{2}-\mathrm{NWs}$ [31]. This absorption 


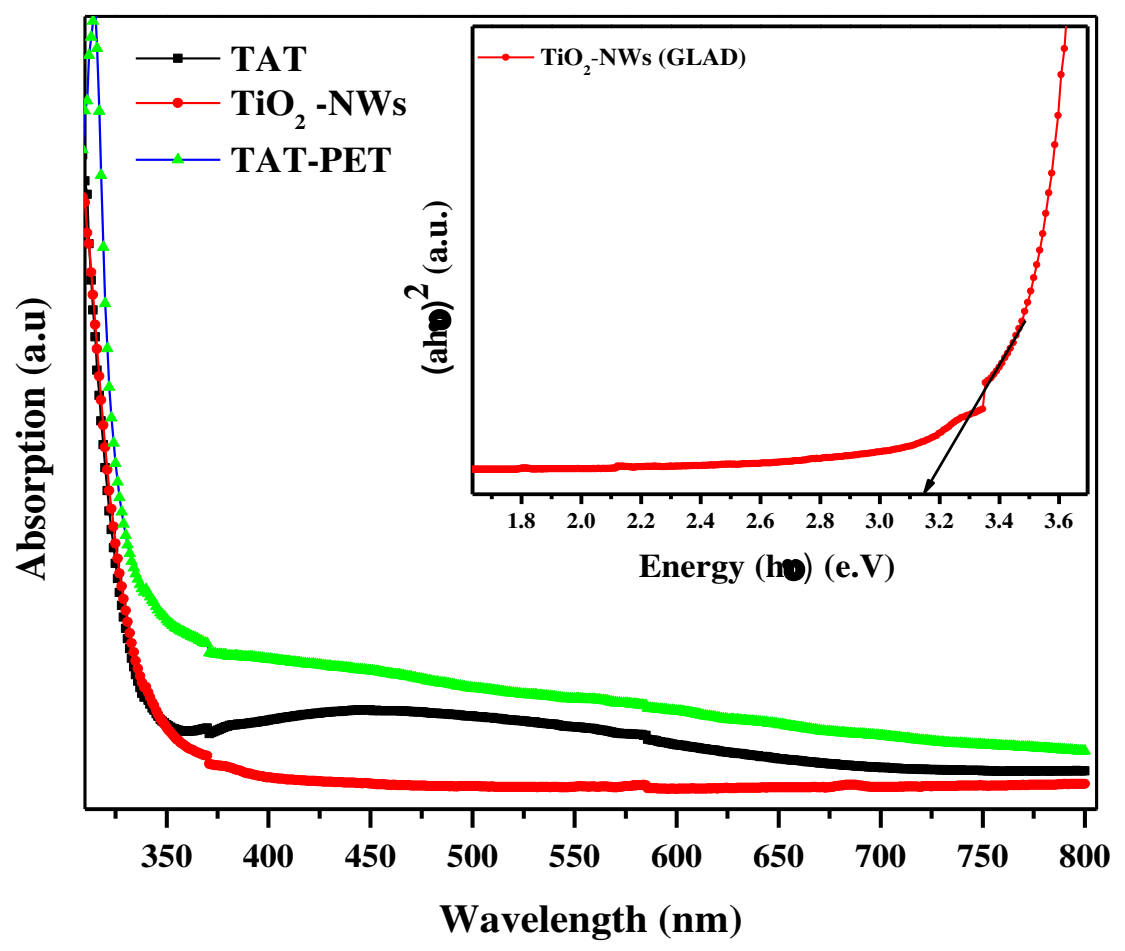

Fig. 5 UV-Vis absorption spectrum of as-deposited $\mathrm{TiO}_{2}-\mathrm{NWs}$ and TAT samples deposited on the glass substrate and PET substrate and the inset shows the bandgap of $\mathrm{TiO}_{2}-\mathrm{NWs}$ using Tauc Plot

enhancement in the visible region may be due to multiple scattering of a photon inside $\mathrm{TiO}_{2}-\mathrm{NWs}_{\text {and }}$ the Surface Plasmon Resonance effect (SPR) of Ag-NPs. It may be noteworthy to mention that the absorption enchantment from the TAT-NWs sample in the visible region around 400 to $600 \mathrm{~nm}$ with the absorption peak at $\sim 463 \mathrm{~nm}$ may be due to the SPR effect that occurs at the interface between Ag-NPs and $\mathrm{TiO}_{2}-\mathrm{NWs}$. Similarly, Sung K. Lim et. al. reported that the absorption peak of Ag-NPs may be tuned from the resonance wavelength of $460 \mathrm{~nm}$ to 540 $\mathrm{nm}( \pm 40 \mathrm{~nm})$ by altering the nanoparticle diameter [32]. It is also interesting to observe that TAT-NWs deposited on PET substrate manifest enhanced optical absorption in the UV and visible spectrum as compare to $\mathrm{TiO}_{2}-\mathrm{NWs}$ and TAT-NWs on the glass substrate. This indicates that the TAT-NWs deposited on PET substrate may be applicable for developing flexible photoanode for Dye-Synthesis Solar cells (DSSCs) and other flexible optoelectronic devices. The inset of Fig. 5 shows the $(\alpha h v)^{2}$ versus ho curve (Tauc Plot), where ho is the photon of energy incident on the $\mathrm{TiO}_{2}-\mathrm{NWs}$ and $\alpha$ is the absorption coefficient. From this Tau plot, the bandgap of $\mathrm{TiO}_{2}-$ NWs is determined by extrapolating the linear portion of the curve to the X-axis of the ( $\alpha$ ho $)^{2}$ and energy curve. The bandgap of the as-deposited $\mathrm{TiO}_{2}-\mathrm{NWs}$ sample from extrapolation is observed to be $\sim 3.15 \mathrm{eV}$. The bandgap obtains from the extrapolation is in good agreement with the bandgap obtain by Kiran Gupta et. al. [33].

\subsubsection{Photoluminescence Spectroscopy}

The broadband PL intensity spectrum of as-deposited $\mathrm{TiO}_{2}-\mathrm{NWs}$ and TAT-NWs samples are plot in Fig. 6, which is excited at $340 \mathrm{~nm}$ wavelength at room temperature. It is observed that the as-deposited $\mathrm{TiO}_{2}-\mathrm{NWs}$ and TATNWs sample shows broad emission with a maximum peak at $\sim 398 \mathrm{~nm}$ and $\sim 397 \mathrm{~nm}$, respectively. The emission peak at $\sim 398 \mathrm{~nm}(\sim 3.12 \mathrm{eV})$ from $\mathrm{TiO}_{2}-\mathrm{NW}$ may be due to the main bandgap emission of anatase $\mathrm{TiO}_{2}-\mathrm{NWs}^{2}$ [34]. However, the TAT sample shows an emission peak at $\sim 397 \mathrm{~nm}(\sim 3.12 \mathrm{eV})$ with lower emission intensity, which may be due to the presence of unoccupied oxygen level created by Ag-NPs on the interface of $\mathrm{TiO}_{2}-\mathrm{NWs}$. However, the main bandgap of $\mathrm{TiO}_{2}$ NWs obtained from the PL analysis supports the bandgap energy extracted from the Tauc plot. It is also observed that the photoluminescence property of $\mathrm{TiO}_{2}-\mathrm{NW}$ decreases due to the reduction of recombination of electrons and holes after the incorporation of Ag-NPs, where the Ag-NPs acting as an electron sink [35]. 


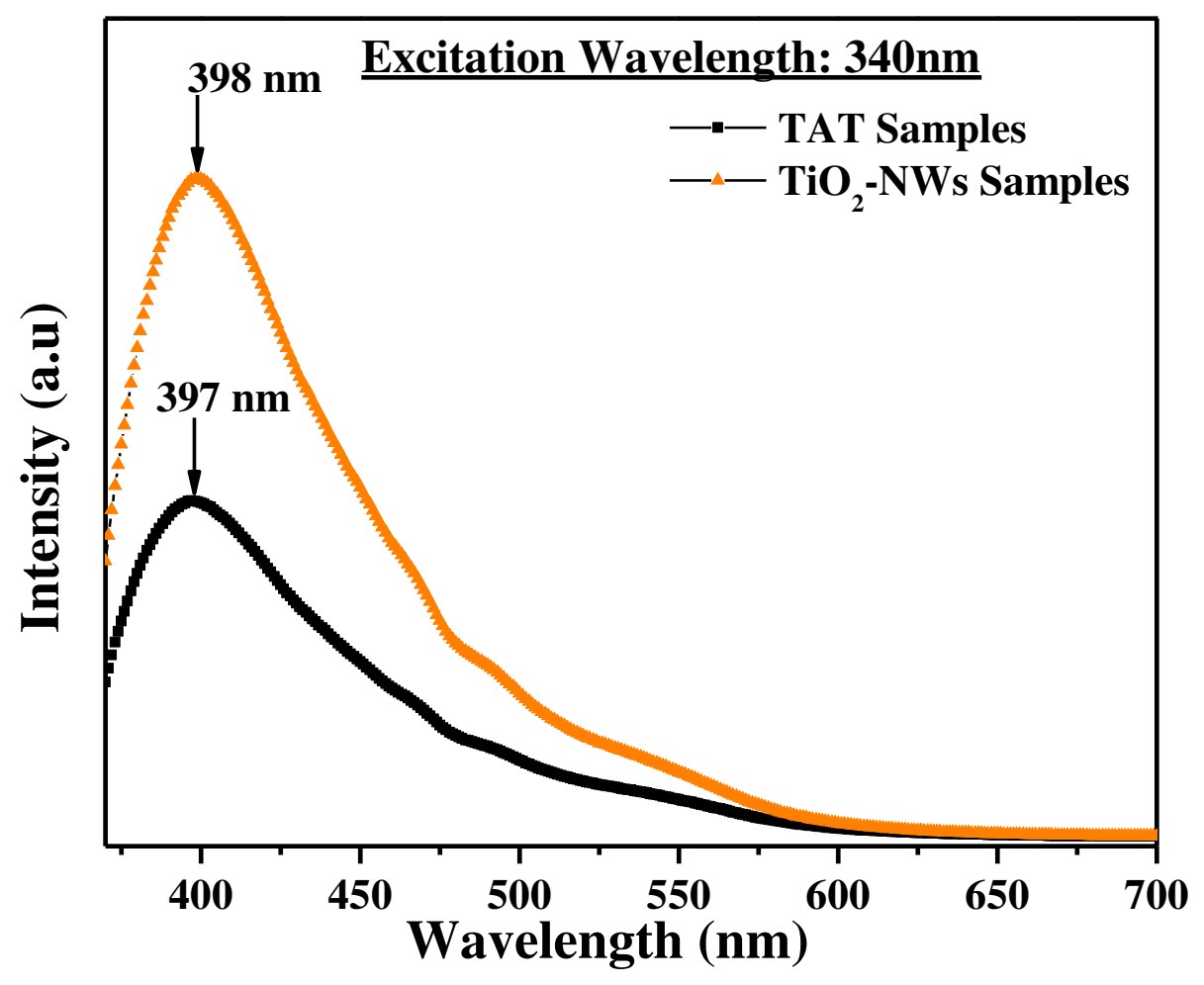

Fig. $6 \mathrm{PL}$ spectrum of as-deposited $\mathrm{TiO}_{2}-\mathrm{NWs}$ and TAT $\left(\mathrm{TiO}_{2}-\mathrm{NWs} / \mathrm{Ag}\right.$ metal NPs)

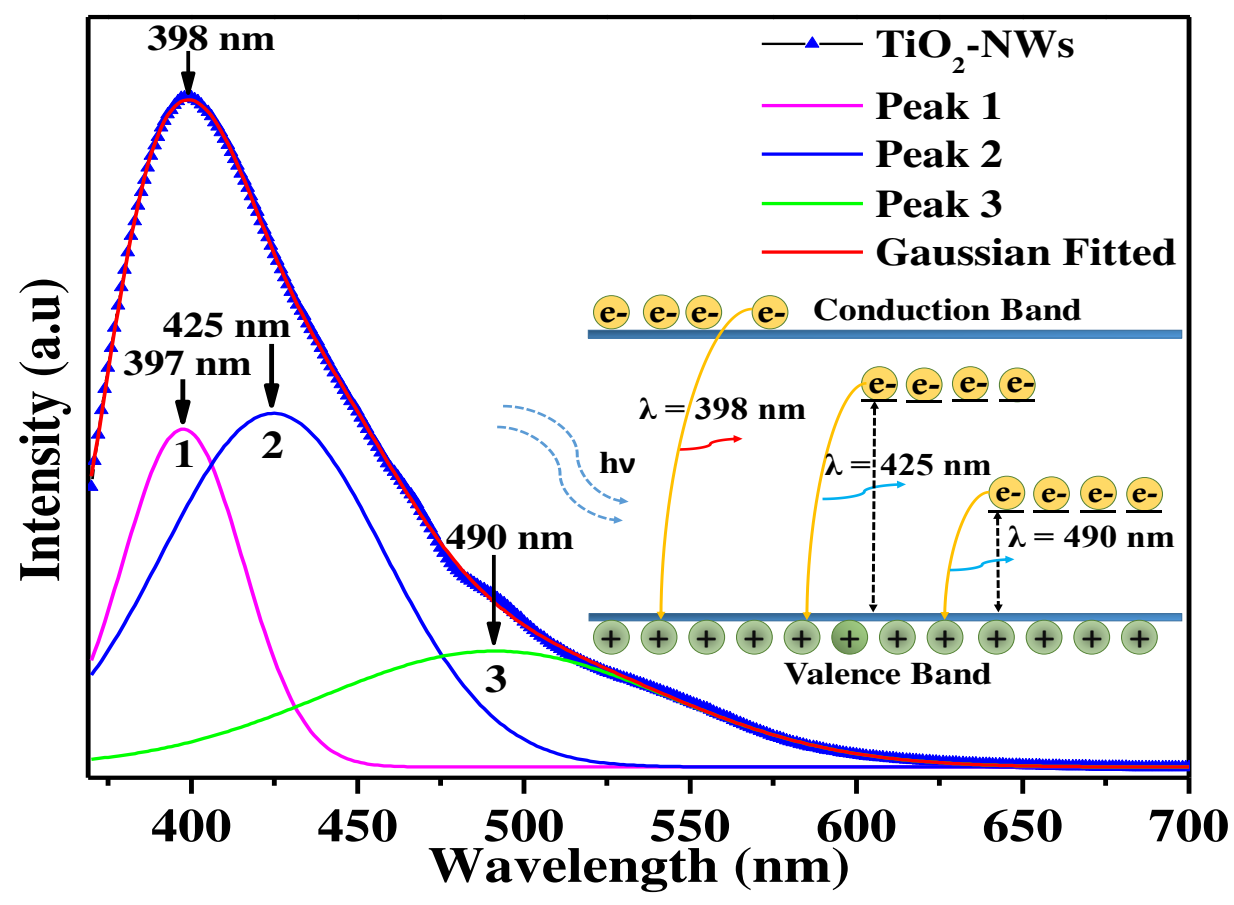

Fig. 7 Gaussian fitted PL peaks of annealed TAT sample

Further, to realize the defects present in $\mathrm{TiO}_{2}$ metal oxide, the Gaussian function was fitted to the PL spectrum of $\mathrm{TiO}_{2}-\mathrm{NWs}$ as shown in Fig. 7. The samples appear maximum emission peak at $\sim 397 \mathrm{~nm}(\sim 3.12 \mathrm{eV})$ which is due to the emission of the main bandgap transition of electrons from the conduction band (CB) to the valence band (VB). On the other hand, the light emission at $\sim 425 \mathrm{~nm}(\sim 2.92 \mathrm{eV})$ may be due to self-trapped excitons transition from the oxygen defects [36]. Further, the emission peak at $\sim 490 \mathrm{~nm}(\sim 2.53 \mathrm{eV})$ is because of the oxygen vacancies at the mid-band gap of $\mathrm{TiO}_{2} \mathrm{NWs}$ [37]. Bandgap energy showing the emission of photons from the defects is illustrated in the inset of Fig. 7. 


\section{Conclusion}

In this work, $\mathrm{TiO}_{2}-\mathrm{NWs}$ and $\mathrm{TiO}_{2}-\mathrm{NWs} / \mathrm{Ag}-\mathrm{NPs} / \mathrm{TiO}_{2}-\mathrm{NWs}$ samples were deposited successfully on Glass and ITO coated PET flexible substrate using the catalytic free GLAD technique. The morphology and structural characterization manifest successfully deposition of $\mathrm{TiO}_{2}-\mathrm{NWs} / \mathrm{Ag}-\mathrm{NPs} / \mathrm{TiO}_{2}-\mathrm{NWs}$ on glass and PET substrate. The top view image of FESEM analysis shows the uniform deposition of TAT-NWs over the glass substrate. Further, the average top diameter of the nanowires is ranging from $\sim 30 \mathrm{~nm}$ to $80 \mathrm{~nm}$. The TEM image of as-deposited $\mathrm{TiO}_{2}$-NWs shows the polycrystalline nature of the sample. Again, the HR-TEM image manifests that the Ag-NPs are successfully deposited in the middle of the NWs. Moreover, the XRD analysis confirms the polycrystalline nature of the $\mathrm{TiO}_{2}$-NWs and the presence of Ag-NPs. It is interesting to observe that the TATNWs sample shows an enhanced absorption spectrum in the near UV and visible regions. However, TAT-NWs deposited on PET substrate shows enhance absorption in the UV and visible region showing potential candidate for flexible electronics application. The bandgap of $\mathrm{TiO}_{2}-\mathrm{NWs}$ obtained from the extrapolation of the Tauc plot is $\sim 3.15 \mathrm{eV}$. Moreover, the bandgap of $\mathrm{TiO}_{2}-\mathrm{NWs}$ obtained from the PL measurement is $\sim 3.12 \mathrm{eV}$, which is almost similar to the bandgap obtained from the Tauc plot. Therefore, the proposed technique of developing metal nanoparticle embedded $\mathrm{TiO}_{2}$-NWs on glass and PET substrate using the catalytic free GLAD technique may be applicable for rigid and flexible optoelectronic applications.

\section{Acknowledgement}

The authors would like to thank the Science and Engineering Research Board (SERB), Government of India for funding this work under File no: ECR/2018/000834. The authors would also like to acknowledge the Department of Electronics and Communication Engineering, Manipur Technical University (MTU) for providing research facilities.

\section{References}

[1] M. Serrapede, U. Savino, M. Castellino, J. Amici, S Bodoardo, Ele Tresso, A. Chiodoni, Li+ Insertion in Nanostructured $\mathrm{TiO}_{2}$ for Energy Storage. Mater. 13 (1), 21 (2020)

[2] Y. Li, J. K. Cooper, W. Liu, C. M. Sutter-Fella, M. Amani, J. W. Beeman, A. Javey, J. W. Ager, Y. Liu, F. M. Toma, I. D. Sharp, Defective $\mathrm{TiO}_{2}$ with high photoconductive gain for efficient and stable planar heterojunction perovskite solar cells. Cryst. 10, 236 (2020)

[3] Bo Weng, Siqi Liu, Zi-Rong Tang, Yi-Jun Xu, One-dimensional nanostructure based materials for versatile photocatalytic applications. RSC Adv. 4, 12685 (2014)

[4] H. C. Weerasinghe, F. Huang, Y. B. Cheng, Fabrication of flexible dye sensitized solar cells on plastic substrates. Nano Energy 2, 174-189 (2013)

[5] B. O' Regan, M. Gratzel, A low-cost high-efficiency solar cell based on dye-sensitized colloidal $\mathrm{TiO}_{2}$ films. Nature 353, 737-740 (1991)

[6] K. Kakiage, Y. Aoyama, T. Yano, K. Oya, Toru Kyomen, M. Hanaya, Fabrication of a high-performance dye-sensitized solar cell with $12.8 \%$ conversion efficiency using organic silyl-anchor dyes. Chem. Commun. 51(29), 6315-6317 (2015)

[7] X. X. Gao, W. Luo, Y. Zhang, R Hu, B. Zhang, A. Zuttel, Y. Feng, M. K. Nazeeruddin, Stable and HighEfficiency Methyl Ammonium-Free Perovskite Solar Cells. Adv. Mater. 32 (9), 1905502 (2020)

[8] T. Kato, J. L. Wu, Y. Hirai, H. Sugimoto, V. Bermudez, Record Efficiency for Thin-Film Polycrystalline Solar Cells Up to $22.9 \%$ Achieved by Cs-Treated Cu (In, Ga) (Se, S)2. IEEE J. Photovolt. 9(1), (2018)

[9] X. Li, G. Huang, N. Zheng, Yon Li, X. Kang, S. Qiao, H. Jiang, W. Chen, R. Yang, High-Efficiency Polymer Solar Cells Over 13.9\% With a High VOC Beyond 1.0 V by Synergistic Effect of Fluorine and Sulfur. Sol. RRL. 3 (4), 1900005 (2019)

[10] Andrew Blakers, Ngwe Zin, Keith R. McIntosh, Kean Fong High Efficiency Silicon Solar Cells. Energy Procedia 33 1-10 (2013)

[11] R.S. Dubey, K. V. Krishnamurthy, S. Singh, Experimental studies of $\mathrm{TiO}_{2}$ nanoparticles synthesized by solgel and solvothermal routes for DSSCs application. Results Phys. 14, 102390 (2019)

[12] X. Qu, Y. Hou, M. Liu, L. Shi, M. Zhang, H. Song, F. Du, Yttrium doped $\mathrm{TiO}_{2}$ porous film photoanode for dye-sensitized solar cells with enhanced photovoltaic performance. Results Phys. 6, 1051-1058 (2016)

[13] Z. A. Garmaroudi, M. R. Mohammadi, Design of $\mathrm{TiO}_{2}$ dye-sensitized solar cell photoanode electrodes with different microstructures and arrangement modes of the layers, J Sol-Gel Sci Technol. 76, 666-678 (2015)

[14] C. Liu, T. Li, Y. Zhang, T. Kong, T. Zhuang, Y. Cui, M. Fang, W. Zhu, Z. Wu, C. Li, Silver nanoparticle modified $\mathrm{TiO}_{2}$ nanotubes with enhanced the efficiency of dye-sensitized solar cells. Micropor Mesopor Mat. 287, 228-233 (2019) 
[15] M. Q. Lokman, S. Shafie, S. Shaban, F. Ahmad, H. Jaafar, R. M. Rosnan, H. Yahaya, S. S. Abdullah, Enhancing Photocurrent Performance Based on Photoanode Thickness and Surface Plasmon Resonance Using Ag- $\mathrm{TiO}_{2}$ Nanocomposites in Dye-Sensitized Solar Cells. Mater. 12, 2111 (2019)

[16] S. Mayumi, Y. Ikeguchi, D. Nakane, Y. Ishikawa, Y. Uraoka, M. Ikeguchi, Effect of Gold Nanoparticle Distribution in $\mathrm{TiO}_{2}$ on the Optical and Electrical Characteristics of Dye-Sensitized Solar Cells. Mater. 12 (513), 1-12 (2017)

[17] R. S. Devan, R. A. Patil, J. H. Lin, Y. R. Ma, One-Dimensional Metal-Oxide Nanostructures: Recent Developments in Synthesis, Characteriztion, and Applications. Adv. Funct. Mater. 22(16), 3326-3370 (2012)

[18] P. Ramasamy, D. H. Lim, J. Kim, J. Kim, A general approach for synthesis of functional metal oxide nanotubes and their application in dye-sensitized solar cells. RSC Adv. 4, 2858-2864 (2014)

[19] X. Yang, Y. Wang, L. Zhang, H. Fu, P. He, D. Han, T. Lawson, X. An, The Use of Tunable Optical Absorption Plasmonic Au and Ag Decorated $\mathrm{TiO}_{2}$ Structures as Effecient Visible Light Photocatalysts. Cryst. 10, 139 (2020)

[20] R. Shakoury, A. Arman, Ş. Ţalu, D. Dastan, C. Luna, S. Rezaee, Stereometric analysis of $\mathrm{TiO}_{2}$ thin films deposited by electron beam ion assisted. Opt. Quantum Electron. 52, 270 (2020)

[21] A. Mondal, J. C. Dhar, P Chinnamuthu, N. K. Singh, K. Kumar Chattopadhyay, S. K. Das, S. Ch. Das, A. Bhattacharyya, Electrical Properties of Vertically Oriented $\mathrm{TiO}_{2} \mathrm{Nanowire}$ Arrays Synthesized by Glancing Angle Deposition Technique. Electron. Mater. Lett. 9 (2), 213-217 (2013)

[22] X. Feng, K. Shankar, O. K. Varghese, M. Paulose, T. J. Latempa, C. A. Grimes, Vertically Aligned Single Crystal $\mathrm{TiO}_{2}$ Nanowire Arrays Grown Directly on Transparent Conducting Oxide Coated Glass: Synthesis Details and Applications. Nano Lett. 8 (11) ,3781-3786 (2008)

[23] B. Shougaijam, R. Swain, C. Ngangbam, T. R. Lenka, Analysis of morphological, structural and electrical properties of annealed $\mathrm{TiO}_{2}$ nanowires deposited by GLAD technique. J. Semicond. 38, 053001(2017)

[24] B. Shougaijam, C. Ngangbam, T. R. Lenka, Plasmon-Sensitized Optoelectronic Properties of Au Nanoparticle-Assisted Vertically Aligned $\mathrm{TiO}_{2}$ Nanowires by GLAD Technique, IEEE Trans Electron Devices. 64 (3), 1127-1133 (2017)

[25] V. Galstyan, A. Vomiero, I. Concina, A. Braga, M. Brisotto, E. Bontempi, G. Faglia, G. Sberveglieri, Vertically Aligned $\mathrm{TiO}_{2}$ Nanotubes on Plastic Substrates for Flexible Solar Cells. Small 7 (17), 2437-2442 (2011)

[26] C.M. Zhou and D. Gall, Growth competition during glancing angle deposition of nanorod honeycomb arrays. Appl. Phys. Lett. 90, 093103 (2007)

[27] A. C. V. Popta, J. Cheng, J. C. Sit, M. J. Brett, Birefringence enhancement in annealed $\mathrm{TiO}_{2}$ thin films. J. Appl. Phys. 102, 013517 (2007)

[28] A. K. M. Muaz, U. Hashim, F. Ibrahim, K. L. Thong, M. S. Mohktar, W. W. Liu, Effect of annealing temperatures on the morphology, optical and electrical properties of $\mathrm{TiO}_{2}$ thin films synthesized by the solgel method and deposited on $\mathrm{Al} / \mathrm{TiO}_{2} / \mathrm{SiO}_{2} / \mathrm{p}-\mathrm{Si}$. Microsyst. Technol. 22, 871-881 (2016)

[29] A. Casu, A. Lamberti, S. Stassi, A. Falqui, Crystallization of $\mathrm{TiO}_{2}$ Nanotubes by In Situ Heating TEM. Nanomaterials. 8, 40 (2018)

[30] Y. Wang, J. Cheng, M. Shahid, M. Zhang, W. Pan, A high-performance $\mathrm{TiO}_{2}$ nanowire UV detector assembled by electrospinning. RSC Adv. 7, 26220 (2017)

[31] A. Ganguly, A. Mondal, J. C. Dhar, N. K. Singh, S. Choudhury, Enhanced visible light absorption by $\mathrm{TiO}_{2}$ film patterned with Ag nanoparticles arrays. Physica E. 54, 326-330 (2013)

[32] S. K. Lim, K. J. Chung, C. K. Kim, D. W. Shin, Y. H. Kim, C. S. Yoon, Surface-plasmon resonance of Ag nanoparticles in polyimide. Int. J. Appl. Phys. 98, 084309 (2005)

[33] K. Gupta, R. P. Singh, A. Pandey, Anjana Pandey, Photocatalytic antibacterial performance of $\mathrm{TiO}_{2}$ and $\mathrm{Ag}$ doped $\mathrm{TiO}_{2}$ against $\mathrm{S}$. aureus. P. aeruginosa. Beilstein J. Nanotechnol. 4, 345-351 (2013)

[34] S. G. Yenchalwar, V. K. Azhagan, and M. V. Shelke, Enhanced photoluminescence and photo activity of plasmon sensitized nSiNWs/TiO 2 heterostructures. Phys.Chem. Chem. Phys. 16 (33), 17786-17791 (2014)

[35] M. Hussain, H. Sun, S. Karim, A. Nisar, M. Khan, A. ul Haq, M. Iqbal, M. Ahmad, Noble metal nanoparticle-functionalized $\mathrm{ZnO}$ nanoflowers for photocatalytic degradation of $\mathrm{RhB}$ dye and electrochemical sensing of hydrogen peroxide. J. Nanopart. Res. 18, 95 (2016)

[36] B. Choudhury, M. Dey, A. Choudhury, Shallow and deep trap emission and luminescence quenching of $\mathrm{TiO}_{2}$ nanoparticles on Cu doping. Appl. Nanosci. 4, 499-506 (2014)

[37] R.V. Nair, G. P.K, V. S. Gummaluria, P.M.G. Nambissanb, C. Vijayan, Large bandgap narrowing in rutile $\mathrm{TiO}_{2}$ aimed towards visible light applications and its correlation with vacancy-type defects history and transformation. J. Phys. D: Appl. Phys. 51, 045107(2018) 
Figures

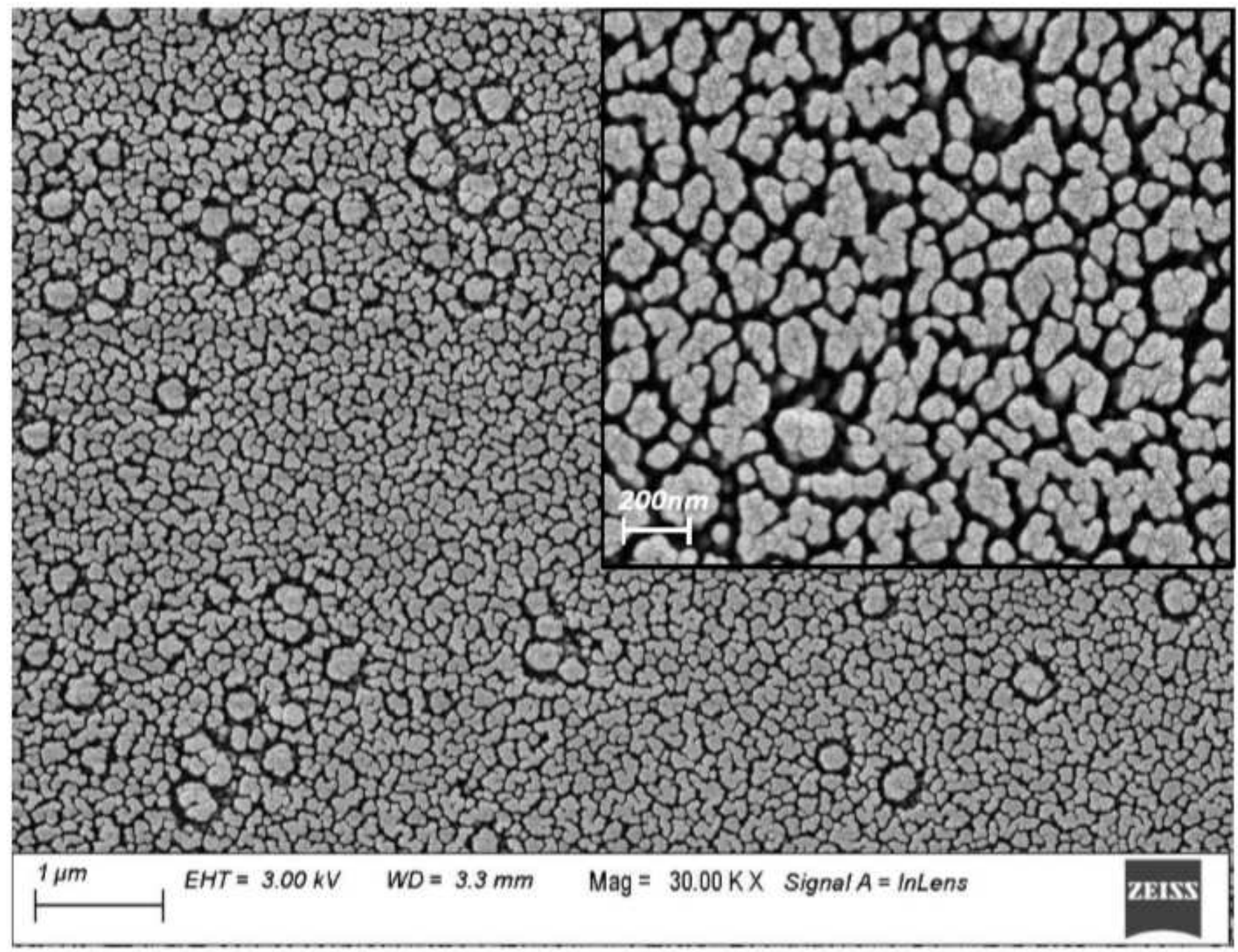

Figure 1

Top view FE-SEM image of as-deposited TAT-NWs sample and inset shows the magnified image showing the porous nature of the sample 

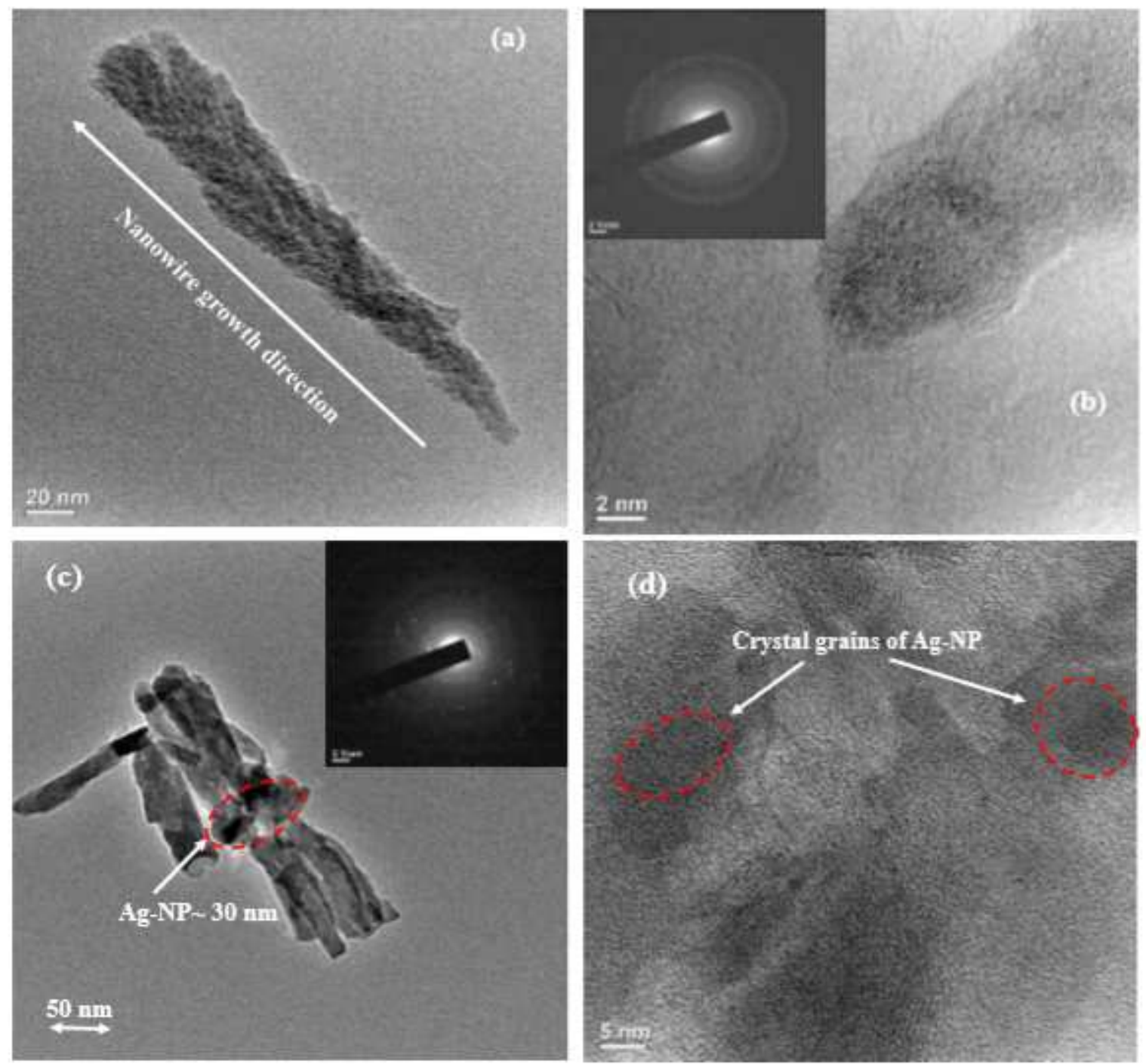

\section{Figure 2}

(a) Shows a typical TEM image of as-deposited TiO2-NWs, (b) shows the magnified image of top portion of TiO2-NWs showing the presence of crystal grain and inset image shows the SEAD results of TiO2-NWs, (c) Shows the TEM image of annealed TAT-NWs sample and SEAD result in inset shows polycrystalline nature, (d) The magnified TEM image of middle portion of TAT-NWs showing the presence of crystal grain of Ag-NPs. 


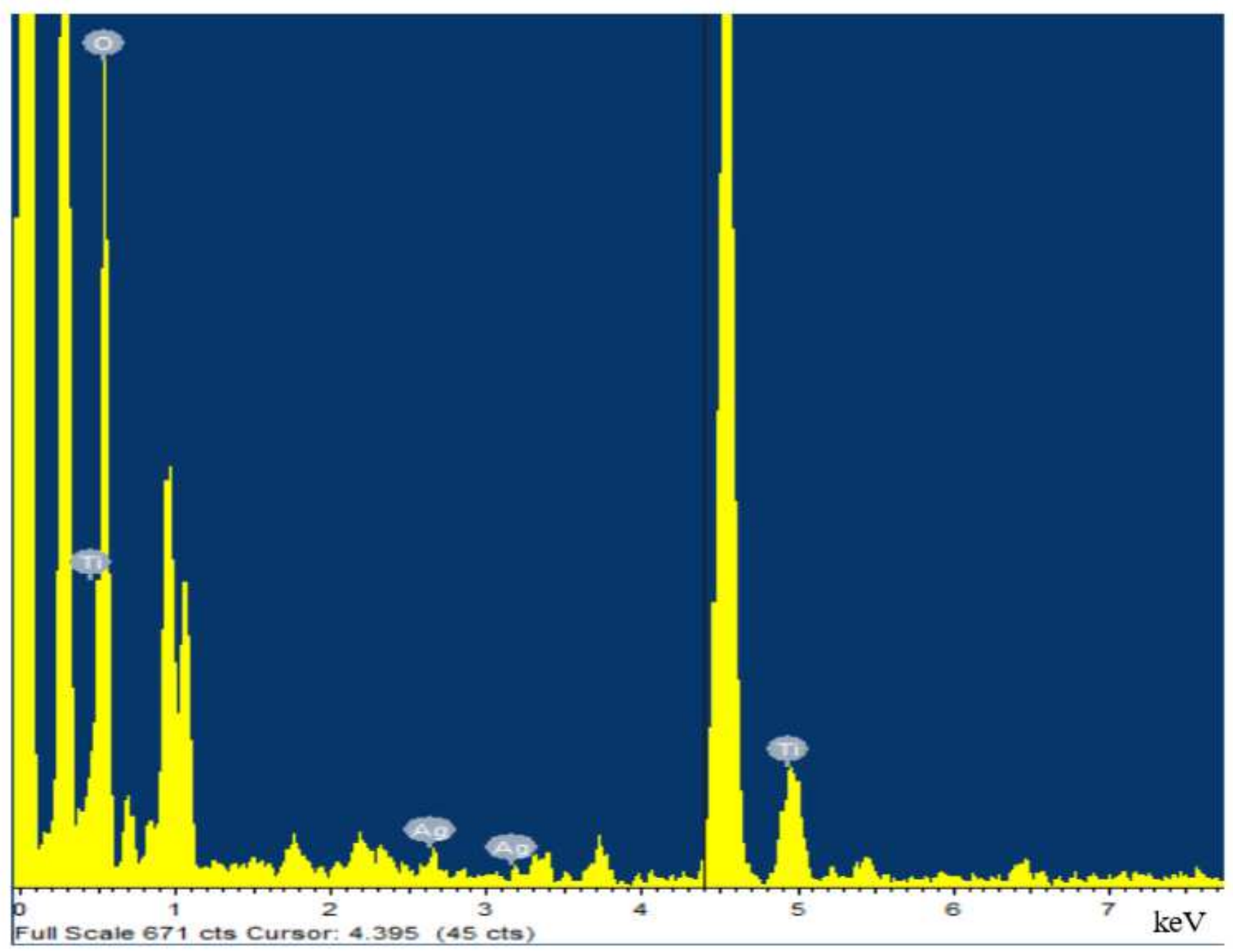

Figure 3

EDX spectrum showing the elemental presence of TAT Sample 


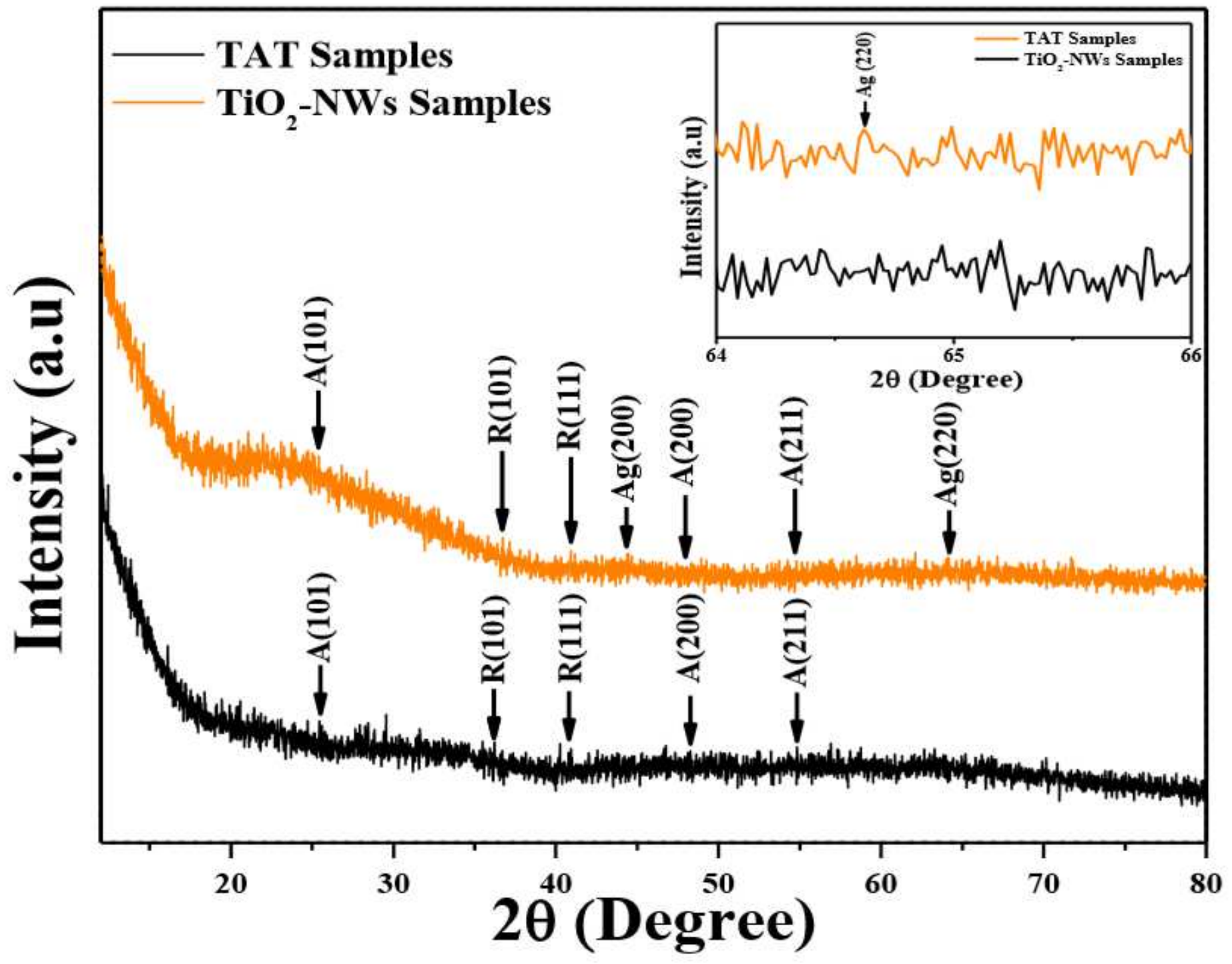

Figure 4

Shows the XRD result of TAT and TiO2 nanowires deposited at room temperature and the inset shows the magnified resolution-showing a peak from $\mathrm{Ag}$ 


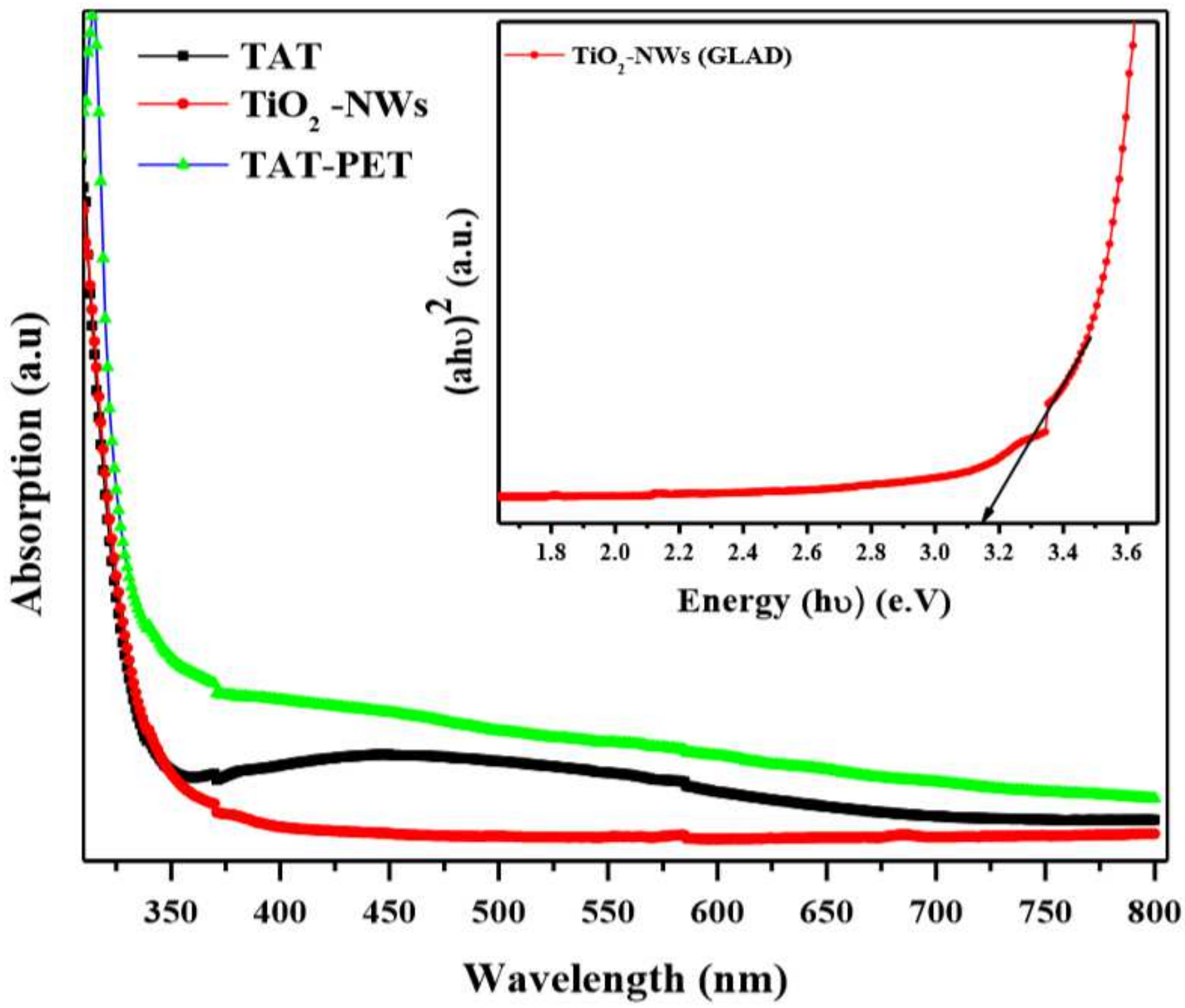

Figure 5

UV-Vis absorption spectrum of as-deposited TiO2-NWs and TAT samples deposited on the glass substrate and PET substrate and the inset shows the bandgap of TiO2-NWs using Tauc Plot 


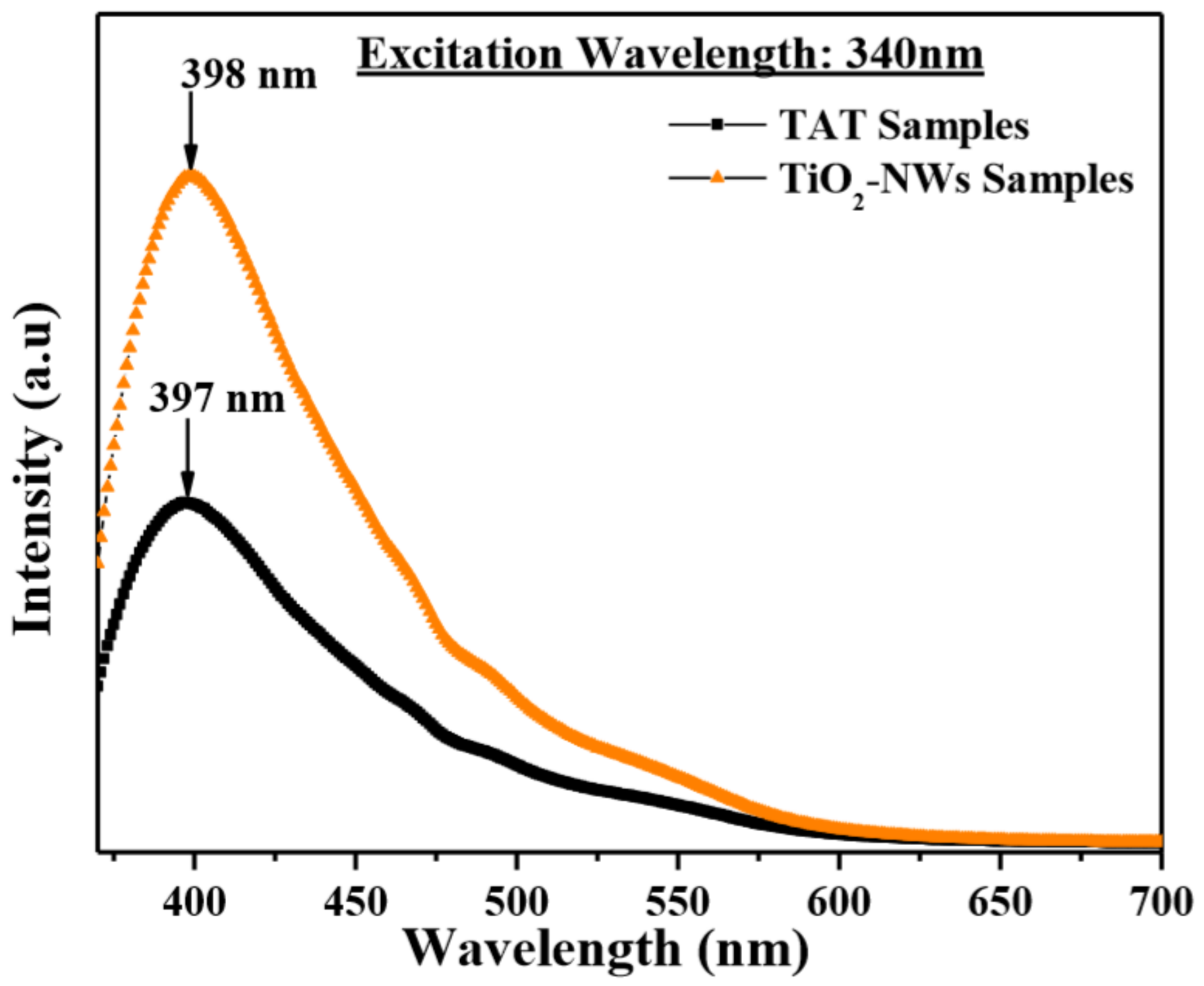

Figure 6

PL spectrum of as-deposited TiO2-NWs and TAT (TiO2-NWs/Ag metal NPs) 


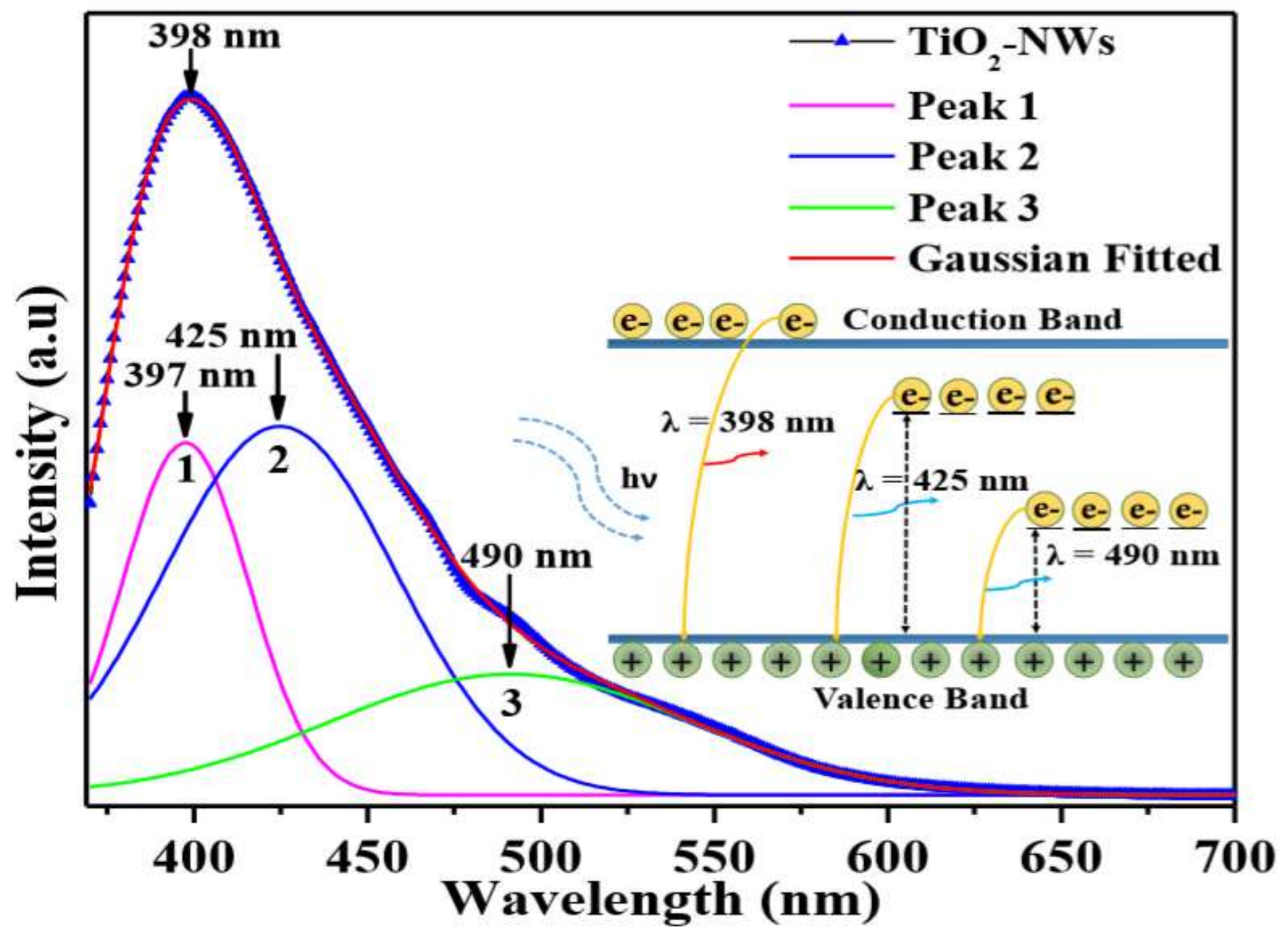

Figure 7

Gaussian fitted PL peaks of annealed TAT sample 